\title{
A case of pleural effusion caused by Mycobacterium fortuitum and Mycobacterium mageritense coinfection
}

\author{
Ryosuke Hirabayashi ${ }^{{ }^{*}}$, Atsushi Nakagawa ${ }^{1}$, Hiroshi Takegawa ${ }^{2}$ and Keisuke Tomii ${ }^{1}$
}

\begin{abstract}
Background: Non-tuberculous mycobacteria cause chronic pulmonary infection, but pleuritis and pleural effusion are rarely associated with infection with non-tuberculous mycobacteria, especially rapid-growing mycobacteria.

Case presentation: A 68-year-old woman with rheumatoid arthritis who was using prednisone, azathioprine, and certolizumab pegol presented complaining of fever, dry cough, and night sweats for the past 2 weeks. Chest examination revealed bilateral opacity that was more pronounced on her right side. Bronchoalveolar lavage fluid and pleural effusion fluid were obtained, and revealed coinfection with Mycobacterium fortuitum and Mycobacterium mageritense. Imipenem/cilastatin, levofloxacin, and minocycline were prescribed for 6 months, and the patient was well and asymptomatic for the subsequent 6 months.

Conclusions: This is the first case report describing pleural effusion associated with coinfection with two different mycobacterial species. If the species cannot be identified, the possibility of mycobacterial coinfection should be considered.
\end{abstract}

Keywords: Coinfection, M. fortuitum, M. mageritense, Nontuberculous mycobacteria, Pleural effusion

\section{Background}

Non-tuberculous mycobacteria (NTM) are common organisms in the environment, and they can cause chronic pulmonary infection. As a group of NTM, rapid-growing mycobacteria (RGM) contain Mycobacterium chelonae, M. fortuitum and M. mageritense [1]. The most common sites of infection with these mycobacteria are pulmonary tissues, skin, bone, and soft tissue.

There are several reports of coinfection with different species of myobacteria. However, NTM infections rarely cause pleural effusion [1] and there are no reports of NTM coinfection associated with pleural effusion. Herein we report a case of pleural effusion caused by $M$. fortuitum and $M$. mageritense coinfection, which was identified from pleural effusion culture and bronchoalveolar lavage (BAL) fluid.

\footnotetext{
* Correspondence: rhirabayashi0405@kcho.jp

${ }^{1}$ Department of Respiratory Medicine, Kobe City Medical Center General Hospital, 2-1-1 Minatojima-minamimachi, Chuo-ku, Kobe, Hyogo 650-0047, Japan

Full list of author information is available at the end of the article
}

\section{Case presentation}

A 68-year-old woman with rheumatoid arthritis was admitted to our hospital complaining of fever, dry cough, and night sweats for the past 2 weeks. She had been diagnosed with rheumatoid arthritis 9 years prior. She had been taking $5 \mathrm{mg} /$ day prednisone and azathioprine, and she had started taking certolizumab pegol from 6 months prior to the current admission.

She reported no malaise, hemoptysis, or weight loss. Other than the aforementioned factors she had no past medical history, including interstitial lung disease or tuberculosis, she was not taking any other medications, and she had no pets. She had never smoked, and she worked as a pharmacist.

On admission her body temperature was $38.2^{\circ} \mathrm{C}$ but other vital signs were not remarkable. Chest $\mathrm{x}$-ray revealed bilateral opacity that was more pronounced on her right side (Fig. 1). Her white blood cell count was $11,700 \mu \mathrm{L}^{-1}$, hemoglobin was $10.0 \mathrm{~g} \mathrm{dL}^{-1}$, and C-reactive protein was $17.12 \mathrm{mg} / \mathrm{dL}$. An HIV assay for HIV-1 and HIV-2 was negative, as was an interferon gamma release assay.

(c) The Author(s). 2019 Open Access This article is distributed under the terms of the Creative Commons Attribution 4.0 International License (http://creativecommons.org/licenses/by/4.0/), which permits unrestricted use, distribution, and reproduction in any medium, provided you give appropriate credit to the original author(s) and the source, provide a link to the Creative Commons license, and indicate if changes were made. The Creative Commons Public Domain Dedication waiver (http://creativecommons.org/publicdomain/zero/1.0/) applies to the data made available in this article, unless otherwise stated. 


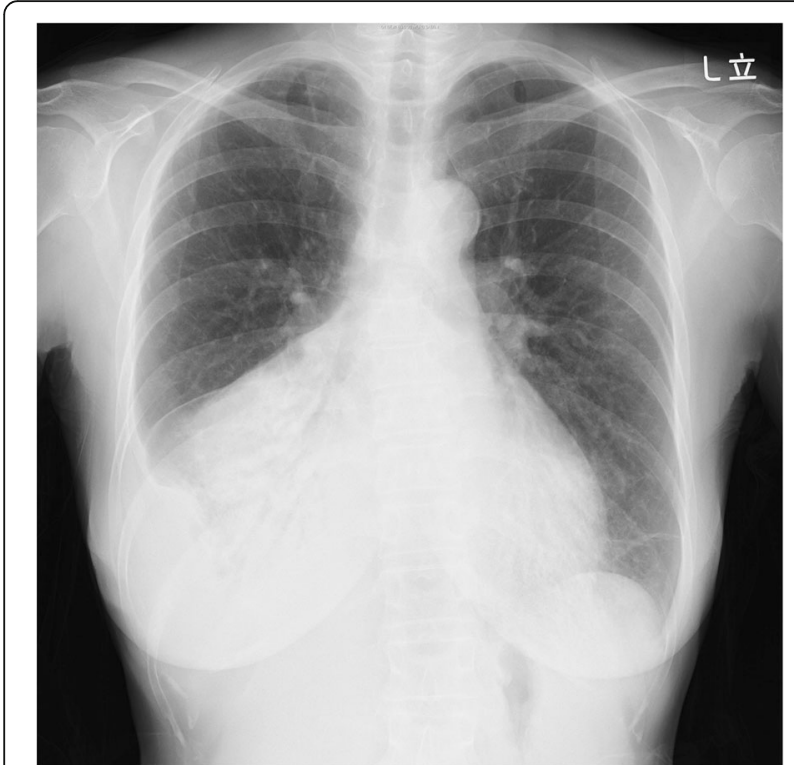

Fig. 1 Chest $x$-ray image on admission

Chest computed tomography (CT) depicted bilateral opacity on her lower lung and pleural effusion on her right thoracic cavity (Fig. 2). Thoracentesis was performed to obtain $150 \mathrm{~mL}$ of pleural effusion fluid from the right side. The white blood cell count of that fluid was $12,700 / \mu \mathrm{L}^{-1}$ (22.7\% lymphocytes), and it contained $5.4 \mathrm{~g}$ protein $/ \mathrm{dL}^{-1}, 2.8 \mathrm{~g}$ albumin $/ \mathrm{dL}^{-1}$, and $1503 \mathrm{U}$ lactate dehydrogenase $/ \mathrm{L}^{-1}$.

BAL fluid and pleural fluid culture were performed. Acid-fast bacilli were detected by Ziehl-Neelsen staining but the species could not identified using a DNA-DNA hybridization method or the matrix-assisted laser

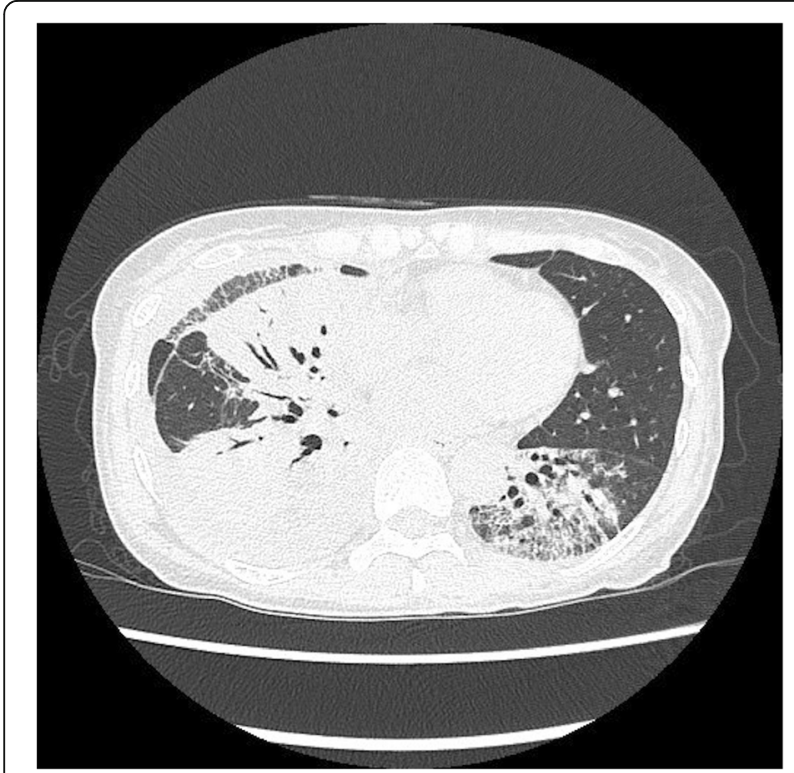

Fig. 2 Chest CT image on admission desorption/ionization time-of-flight mass spectrometry (MALDI-TOF MS). The drug susceptibility testing revealed resistance to amikacin (minimum inhibitory concentration $>32 \mu \mathrm{g} / \mathrm{mL}$ ), but reexamination for microbial identification and the drug susceptibility testing suggested susceptibility to amikacin. To investigate contamination or mycobacterial coinfection, growth enhancement on Middlebrook 7H11C agar plate testing was performed. Two types of colonies were developed from both BAL and pleural fluid culture, and the causative microorganisms were identified as $M$. fortuitum and M. mageritense by MALDI-TOF MS-with each of the hsp65 and rpoB region sequences respectively exhibiting 100 and $99.0 \%$ matching with $M$. fortuitum, and 98.4 and $99.0 \%$ matching with $M$. mageritense.

Eight weeks of treatment with imipenem/cilastatin (500 mg every $6 \mathrm{~h}$ intravenously), minocycline (100 mg orally twice a day), and levofloxacin (500 mg orally once a day) were initiated, followed by 4 months maintenance therapy by minocycline and levofloxacin. After the maintenance therapy, Her symptoms and bilateral pulmonary opacity were improved (Figs. 3 and 4). Now we follow her for 2 years, her sputum culture is still negative and her chest $\mathrm{x}$-ray is still clear.

\section{Discussion and conclusion}

This is the first report of pleural effusion caused by two species of RGM coinfection. There are several reports of pulmonary infection or pleural effusion caused by the coinfection of mycobacteria, which include NTM and Mycobacterium tuberculosis complex (MTC) coinfection or different subspecies of $M$. avium complex coinfection. In cases of pulmonary infection however, it is difficult to

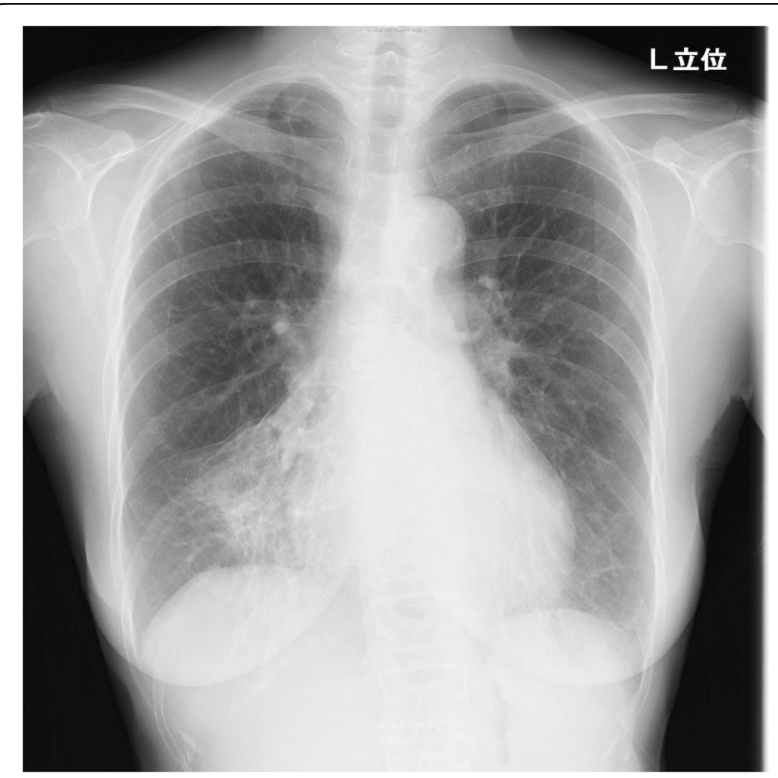

Fig. 3 Chest $x$-ray image after the treatment 


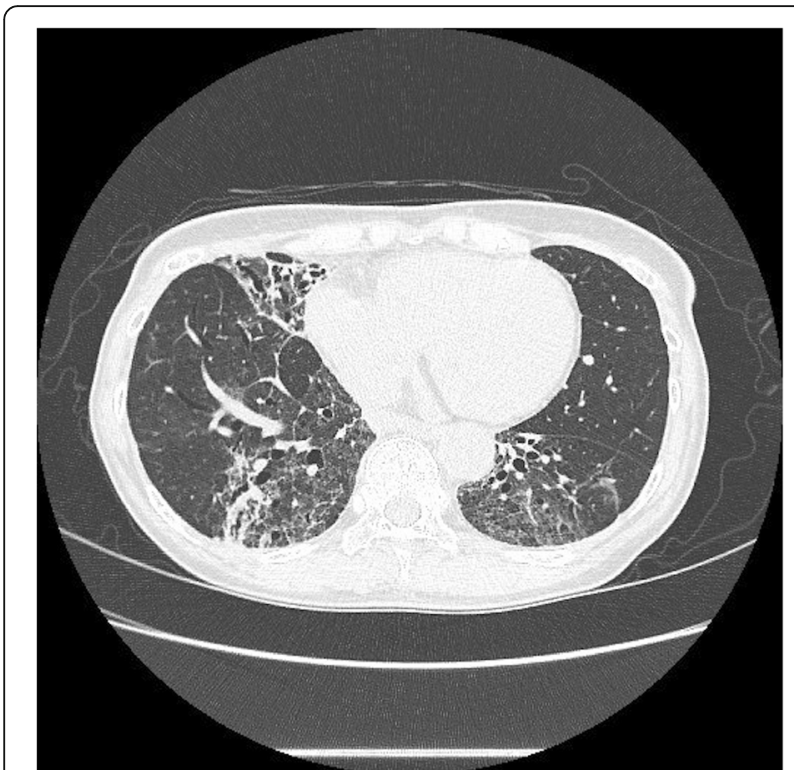

Fig. 4 Chest $C T$ image after the treatment

prove coinfection from sputum because it is easily colonized by NTM, and often it is difficult to isolate or identify the species involved. Aseptic collection of body fluid such as pleural effusion via needle aspiration is better for the verification of NTM coinfection [1], but NTM rarely causes pleural effusion than MTC. In the present case NTM coinfection was verified via pleural effusion and BAL. there are no previous reports of coinfection with nontuberculous mycobacteria in pleural effusions and this is the first report about it.

Neither DNA-DNA hybridization nor MALDI-TOF MS identified the species, and the aforementioned contradictory results of drug susceptibility testing were obtained twice. MALDI-TOF MS is one of the recommended molecular methods for identifying NTM [2], but the method is limited with regard to specificity in this respect $(52.8-98.6 \%)[3,4]$. If the species cannot be identified, mycobacterial coinfection should be considered.

In conclusion, this report described a case of pleural effusion caused by $M$. fortuitum and $M$. mageritense coinfection. In cases of mycobacterial infection where microbiological testing cannot identify the species involved, coinfection should be considered and more extensive investigation to determine the species should be undertaken.

\footnotetext{
Abbreviations

BAL: Bronchoalveolar lavage; MALDI-TOF MS: Matrix-assisted laser desorption/ ionization time-of-flight mass spectrometry; MTC: Mycobacterium tuberculosis complex; NTM: Non-tuberculosis mycobacteria; RGM: Rapid-growing mycobacteria
}

\section{Authors' contributions}

$\mathrm{RH}$ was a major contributor in writing the manuscript. AN considered and decided the clinical testing or treatment for this patient. HT cultured and identified these mycobacteria. KT also was a major contributor in writing the manuscript. All authors read and approved the final manuscript.

\section{Funding}

The authors declare that they have no sources of funding.

\section{Availability of data and materials}

The datasets used or analysed during the current study are available from the corresponding author on reasonable request.

Ethics approval and consent to participate Not applicable.

\section{Consent for publication}

Written informed consent was obtained from the patient for publication of this case report and any accompanying images. A copy of the written consent is available for review by the Editor of this journal.

\section{Competing interests}

The authors declare that they have no competing interests.

\section{Author details}

'Department of Respiratory Medicine, Kobe City Medical Center General Hospital, 2-1-1 Minatojima-minamimachi, Chuo-ku, Kobe, Hyogo 650-0047, Japan. ${ }^{2}$ Department of Laboratory Medicine, Kobe City Nishi-Kobe Medical Center, 5-7-1 Kouji-dai, Nishi-ku, Kobe, Hyogo 651-2273, Japan.

Received: 15 May 2019 Accepted: 7 August 2019

Published online: 15 August 2019

\section{References}

1. Griffith DE, Aksamit T, Brown-Elliott BA, et al. An official ATS/IDSA statement: diagnosis, treatment, and prevention of nontuberculous mycobacterial diseases. Am J Respir Crit Care Med. 2007;175(4):367-416.

2. Haworth CS, Floto RA. Introducing the new BTS guideline: management of non-tuberculous mycobacterial pulmonary disease (NTM-PD). Thorax. 2017;72(11):969-70.

3. Quinlan P, Phelan E, Doyle M. Matrix-assisted laser desorption/ionisation time-of-flight (MALDI-TOF) mass spectrometry (MS) for the identification of mycobacteria from MBBacT ALERT 3D liquid cultures and LowensteinJensen (LJ) solid cultures. J Clin Pathol. 2015;68(3):229-35.

4. Mediavilla-Gradolph MC, De Toro-Peinado I, Bermudez-Ruiz MP, et al. Use of MALDI-TOF MS for identification of nontuberculous mycobacterium species isolated from clinical specimens. Biomed Res Int. 2015;2015:854078.

\section{Publisher's Note}

Springer Nature remains neutral with regard to jurisdictional claims in published maps and institutional affiliations.

Ready to submit your research? Choose BMC and benefit from:

- fast, convenient online submission

- thorough peer review by experienced researchers in your field

- rapid publication on acceptance

- support for research data, including large and complex data types

- gold Open Access which fosters wider collaboration and increased citations

- maximum visibility for your research: over $100 \mathrm{M}$ website views per year

At BMC, research is always in progress.

Learn more biomedcentral.com/submissions 